\title{
Medikal Ekspulsif Tedavi: Yeni Olan Nedir?
}

\author{
Ali $\operatorname{Atan}^{1}$
}

${ }^{1}$ Gazi Üniversitesi, Tıp Fakültesi, Üroloji Anabilim Dalı, Ankara

\section{Giriş}

$\mathrm{M}$ edikal ekspulsif tedavi'nin (MET) amacı taş düşmesini arttırma, taş düşme süresini kısaltma, hospitalizasyon ve girişim ihtiyacını azaltma, risk ve komplikasyonları engelleme (taş ve işlem ile ilgili), iş gücü kaybını önleme ve maliyeti düşürmedir $(1,2)$. MET uygulama kararı bazı kriterlere bağlıdır. Bunlar taşın lokalizasyonu, taşın büyüklüğü, anatomik durum ve hastanın tercihidir (3). Taşın üriner sistem içerisinde bulunduğu yer çok önemlidir. Üriner sistem taşlarının \%20'si üreterde ve üreter taşlarının ise \%70'i distal üreterde lokalizedir (4). Taşın büyüklüğü de MET uygulamak için çok önemlidir. Eski çalışmalarda klasik olarak 5 mm'nin altındaki taşların sadece sıvı alımının artırılması ve analjezik kullanımı ile spontan olarak düşebileceği belirtilmekteydi. Yani MET uygulamak için taş büyüklüğünün alt sınırı 5 mm olarak kabul edilirdi. Ancak yeni Avrupa Üroloji Derneği (EAU) kılavuzunda kesin bir sınır değer verilememesine karşın $6 \mathrm{~mm}$ 'den büyük taşlar için kullanılabileceği önerilmektedir. (5). MET vermek için kabul edilen üst sınır $10 \mathrm{~mm}$ olarak kabul edilmektedir (6).

MET için kullanılan ilaçlar alfa blokerler, kalsiyum kanal blokeri (nifedipin), kortikosteroidler ve fosfodiesteraz tip-5 inhibitörü (PDE-5i) ilaçlardır. Alfa blokerlerin ve nifedipinin karşılaştırıldığı pek çok çalışma yapılmıştır. Bu çalışmalardan elde edilen sonuçlar da farklılıklar vardır. Bir grup çalışmada alfa blokerler ve nifedipin benzer etkinlikte bulunmasına karŞın (6-8), bir grup çalışmada ise alfa blokerlerin daha faydalı olduğu saptanmıştır (9-13). Bizim tamsulosin ve nifedipini karşılaştırdığımız çalışmamızda ise taş düşme oranı tamsulosin grubunda \%76, nifedipin grubunda \%64 oraninda bulunmakla birlikte; aradaki fark istatistiksel olarak anlamlı bulunmamıştır (14). Bir önceki EAU kılavuzunda hem alfa blokerler; hem de kalsiyum kanal blokeri kullanımı önerilirken yeni EAU kilavuzunda alfa blokerlerin ve kalsiyum kanal blokerlerinden yalnızca nifedipinin MET amacıyla kullanıldığında etkili olduğu; ancak alfa blokerlerin daha başarılı olduğu belirtilmektedir. Bu nedenle yeni kılavuzda kalsiyum kanal blokerinin bir grup olarak kullanımı ile ilgili öneri çıkarılmıştır (5). Kortikosteroid kullanımının faydalı olduğunu belirten çalışmalar olmasına karşın kılavuzlarda monoterapi olarak kullanımı önerilmemektedir. Ancak diğer ilaçlar ile kombine kullanılabileceği belirtilmektedir $(5,13)$.

PDE-5 inhibitörü ilaçlar 1998 yılından beri klinik kullanımdadır. İlk olarak erektil disfonksiyon tedavisinde kullanılırken, son yıllarda benign prostat hiperplazisi ile ilişkili alt üriner sistem yakınmalarının tedavisinde de kullanılmaya başlanmıştır. PDE-5i'lerine olan ilginin fazla olması ve çok sayıda çalışma yapılması neticesinde PDE-5i'lerinin üreterde de relaksasyon yaptıkları saptanmıştır. Üreterdeki relaksasyon yapıcı etki fazladan aza doğru sırası ile vardenafil, sildenafil ve tadalafil şeklinde bulunmuştur (15). Ancak henüz PDE-5i'lerinin MET olarak kullanımı konusunda yeterli veriye sahip değiliz.

Üreter düz adalelerinin kontraksiyonunda sempatik sinir sistemi de çok önemlidir. Alfa adrenerjik reseptörlerin en fazla bulunduğu alan distal üreter olmasına karşın tüm üreter segmentlerinde alfa adrenerjik reseptör ekspresyonu vardır. Reseptörlerin üreterde yoğun olarak bulunma sırası alfa-1d, alfa-1a ve alfa-1b şeklindedir (16). Alfa blokerler ile alfa reseptörlerin blokajı tonik propulsif kasılmaları devam ettirir iken düzensiz, aşırı peristaltizm sıklığını azaltır $(17,18)$. Ayrıca C-lifleri veya sempatik postganglionik nöronları etkileyerek SSS'e visseral yansıyan ağrının iletimini bloke ederler (19). MET amaciyla sıklıkla tamsulosin kullanılmasına karşın terazosin, doksazosin ve alfuzosinin kullanıldı̆̆ da vardır. Alfa blokerlerin karşılaştırıldığı bu çalışmalarda etkinlik farkının olmadığı, faydanın sınıf etkisinden kaynaklandığı belirtilmektedir (20-22). Ancak silodosinin kullanıldığ daha yeni çalışmalarda farklı sonuçlar elde edilmiştir. Huang ve ark.'larının yaptığı bir meta-analiz ve sistemik derleme çalışmasında silodosinin MET için kullanıldığındaki etkinliği incelenmiştir. Bu derlemeye 9 çalışma dâhil edilmiştir. Çalışmaların 4 tanesinde silodosin ve plasebo karşılaştırılırken; 4 tanesinde silodosin ve tamsulosin, 1 tanesinde silodosin, tamsulosin ve tadalafil karşılaştırılmıştır (23). Bu çalışmalarda silodosinin taş düşürme oranı \%83.5, taş düşürme süresi ise 11 gün bulunmuş; tamsulosinin ise taş düşürme oranı \%66.9, taş düşürme süresi ise 14 gün olarak saptanmıştır. Yazarlar bu sonuçlara dayanarak silodosinin, plasebo ve tamsulosine göre daha fazla oranda taş düşürülmesine yardımcı olduğunu ve daha iyi ağrı kontrolü sağladığını belirtmektedirler. Bu durum alfa reseptörlerin üreterdeki dağılımına ve bu reseptörler üzerindeki etkisine bağlanmaktadır. Üreterde alfa-1a reseptörler \%26, alfa-1d reseptörler \%51 ve alfa- $1 \mathrm{~b}$ reseptörler $\% 23$ oranında bulunmaktadır. Alfa-1a reseptörlere selektivite silodosin için 162, tamsulosin için 9.5 ve alfa-1d reseptörlere selektivite silodosin için 3.2, tamsulosin için 3 bulunmuştur. Distal üreterde alfa-1d ve alfa-1a reseptörlerin fazla olduğu göz önüne alındığında silodosinin neden fazla etkin olduğu görülmektedir (23). Bu derlemede yer alan bir çalışmada Silodosin $(8 \mathrm{mg} / \mathrm{g})$, Tamsulosin $(0.4 \mathrm{mg} / \mathrm{g})$ ve Tadalafil $(10$ 
mg/g) karşılaştırılmıştır (24). Taş düşürme oranları ve günleri; Silodosin için \%83.3 ve 14.8 gün, Tamsulosin için \%64.4 ve 16.5 gün, Tadalafil için \%66.6 ve 16.2 gün bulunmuştur. Ortalama analjezik kullanım ihtiyacı silodosin grubunda daha az iken diğer 2 grup aynı olarak saptanmıştır.

MET uygulama süresi 4 haftayı aşmamalıdır. MET başladıktan sonra kesin olmamakla beraber 1. gün ile 14. gün arasında taşın lokalizasyonu ve hidronefrozun derecesi açısindan hasta kontrol edilmelidir (5).

Hekimlerin MET kullanımı ile ilgili düşünceleri de değişim göstermiştir. Brede ve ark.'larının bir çalışmasında 2003 yılında hekimlerin \%78'i MET kullanmazken, sadece \%22'si MET uygulamaktaydı. MET kullananların tamamı kalsiyum kanal blokeri olan nifedipin vermekteydi. MET kullanma oranı 2005 yılında \%57'ye yükselmiştir. MET amacıyla \%18 oranında alfa bloker, \%39 oranında nifedipin verilmiştir. 2007 yılında ise MET kullanımı \%78'e yükselirke, MET kullanmama oranı \%22 düzeyine inmiştir. MET reçete eden hekimlerin $\% 76$ 's alfa bloker, sadece $\% 2$ 'si nifedipin vermekteydi (2).

Hastaların bir grubu taşın lokalizasyonu ve büyüklüğü uygun olmasına karşın MET'e yeterli cevabı vermemektedir. Bu amaçla yeni bir çalışmada MET başarısının öngörülmesini sağlayacak parametreler incelenmiştir (25). Bu çalışmada yaş, vücut kitle indeksi ve taşın Hounsfield ünitesi MET başarısı için anlamlı olmamasına karşın; MET'in başarılı ve başarısız olduğu gruplarda hidronefroz derecesi, taşın büyüklüğü, proksimal ureter çapı ve üreter duvar kalınlığı anlamlı olarak farklı bulunmuştur. Taşın büyüklüğü, hidronefroz derecesi, proksimal üreter çapı ve üreter duvar kalınlığı arttıkça MET başarısının azaldı $\breve{g}_{1}$ belirtilmektedir. Bu klinik parametrelere ek olarak CRP düzeyleri ile MET'nin etkin olup olmayacağ 2013 yılında yapılmış bir çalışmada araştırılmıştır. Bu çalışmada MET faydalı grupta CRP $16.45+2.58$, MET faydasız grupta CRP 39.67 + 6.30 saptanmıştır. Yazar CRP için sınır değeri $21.9 \mathrm{mg} / \mathrm{L}$ olarak belirtmiştir. Eğer CRP bu değerin altında ise MET'nin uygulanabileceği ancak bu değerin üzerinde ise endoskopik işlemin düşünülmesinin uygun olacağ sonucuna varılmıştır (26).

Bazı özel durumlarda da MET düşünülmelidir. Özellikle taş tedavisinde sık olarak kullanılan ESWL sonrasında MET faydalı olmaktadır. ESWL sonrası MET ile analjezik ihtiyacı azalmakta, taşsızlık oranı artmaktadır $(27,28)$. Yeni bir çalışmada renal ve proksimal ureter taşlarında ESWL sonrası MET faydalı bulunmuştur ve ek işlem ihtiyacını azaltmıştır (29). Yeni EAU kılavuzunda da MET ile ESWL sonrası taş pasajının arttığı ve ağrının azaldığı belirtilmektedir (5). MET klasik olarak alt üreter taşlarında kullanılmasına karşın bazı çalışmalarda proksimal ureter taşlarında da uygulanmıştır. Bu çalışmalarda MET'nin $10 \mathrm{~mm}$ altı proksimal taşları daha da aşağıya indirdiği gösterilmiştir (30). Rijit veya fleksible ureterenoskopi (URS) sonrası MET kullanımının koliği azalttığı ve taşsızlığı arttırdığı saptanmıştır (31). URS sonrası double J (DJ) stent takılması sik yapılan bir uygulamadır. DJ stent sonrası alfa blokerlerin stent rahatsızlığını azalttığı saptanmıştır ve etkinliğin her alfa bloker için benzer olduğu belirtilmektedir $(32,33)$. EAU kılavuzunda da alfa blokerlerin stent rahatsızlığını azalttığı ifade edilmektedir.

Ancak her hastaya MET uygun değildir. MET verilmemesi gereken hastalar vardır $(5,24,34,35)$. Bunlar; semptomatik üreter taşı, yüksek ateşi, ilerleyen hidronefrozu, akut veya kronik renal yetmezliği, soliter böbreği, çok sayıda üreter taşı bulunan, hemen müdahale talep eden, mesleği denizcilik veya pilot olan, 65 yaş üzerinde olan, diyabeti veya peptik ülseri bulunan, açık cerrahi veya endoskopik işlem öyküsü olan, beta bloker, kalsiyum antagonistleri, nitrat grubu ilaç kullanım zorunluluğu olan, gebe veya bebek emzirmesi gereken hastalardır.

Sonuç olarak, MET için kullanılan ilaçlar bu amaçla kullanım ruhsatına sahip değildirler. Bu konuda hastalar bilgilendirilmelidir. Hem üroloji uzmanları hem de üroloji dişındaki hekimler MET konusunda bilgilendirilmelidirler. Yenilik olarak nifedipin haricindeki kalsiyum kanal blokerlerinin kullanımı önerilmemektedir ve silodosin en başarılı alfa bloker olarak görünmektedir. Net olmamakla birlikte MET kullanımı için taş büyüklüğünün alt sınırı $6 \mathrm{~mm}$ 'ye çıkmış ve zaman içerisinde MET kullanımı oldukça artmıştır, Diğer taraftan, ESWL, URS ve DJ stent takılması sonrası MET kullanımı tavsiye edilmeye başlanmıştır. Bundan sonraki süreçte orta-üst üreter taşlarında MET kullanımı ile ilgili çalışmaların artması, PDE-5i ve silodosin kombinasyonunun denenmesi ve MET başarısını belirleyen klinik ve laboratuar kriterlerinin (CRP) araştırılması gündemimizde olmalıdır.

\section{Kaynaklar}

1. Sterrett SP, Nakada SY. Medical expulsive therapy. Curr Opin Urol 18: 210-23, 2008

2. Brede C, Hollingsworth JM, Faerber GJ, Taylor JS, Wolf JS Jr. Medical expulsive therapy for ureteral calculi in the real world: targeted education increases use and improves patient outcome. J Urol 183: 585-589, 2010.

3. Bensalah K, Pearle M, Lotan Y. Cost-effectiveness of medical expulsive therapy using alpha-blockers for the treatment of distal ureteral stones. Eur Urol 53: 411-418, 2008.

4. Carstensen HE, Hansen TS. Stones in the ureter. Acta Chir Scand Suppl 433: 66-71, 1973.

5. Turk C, Petrik A, Sarica K, Seitz C, Skolarikos A, Straub $\mathrm{M}$, Thomas Knoll. EAU Guidelines on Diagnosis and Conservative Management of Urolithiasis. Eur Urol 69: 468-474, 2016.

6. Singh A, Alter HJ, Littlepage A. A systematic review of medical therapy to facilitate passage of ureteral calculi. Ann Emerg Med 50: 552-563, 2007.

7. Hollingsworth JM, Rogers MA, Kaufman SR, Bradford TJ, Saint S, Wei JT, Hollenbeck BK. Medical therapy to facilitate urinary stone passage: a meta-analysis. Lancet. 368: 1171-9, 2006.

8. Seitz C, Liatsikos E, Porpiglia F, Tiselius HG, Zwergel U. Medical therapy to facilitate the passage of stones: what is the evidence? Eur Urol. 56: 455-471, 2009.

9. Porpiglia F, Ghignone G, Fiori C, Fontana D, Scarpa RM. Nifedipine versus tamsulosin for the management of lower ureteral stones. J Urol. 172: 568-571, 2004.

10. Ye Z, Yang H, Li H, Zhang X, Deng Y, Zeng G, et al. A multicentre, prospective, randomized trial: comparative efficacy of tamsulosin and nifedipine in medical expulsive therapy for distal ureteric stones with renal colic. BJU Int 108: 276-279, 2011.

11. Gandhi HR, Agrawal C. The efficacy of tamsulosin vs. nifedipine for the medical expulsive therapy of distal ureteric stones: A randomised clinical trial. Arab J Urol 11: 405-410, 2013. 
12. Cao D, Yang L, Liu L, Yuan H, Qian S, Lv X, et al. A comparison of nifedipine and tamsulosin as medical expulsive therapy for the management of lower ureteral stones without ESWL. Sci Rep. 2014 Jun 11;4: 5254. doi: 10.1038/srep05254.

13. Bos D, Kapoor An Update on medical expulsive therapy for distal ureteral stones: Beyond alpha-blockers. Can Urol Assoc J 8: 442-445, 2014.

14. Balci M, Tuncel A, Aydin O, Aslan Y, Guzel O, Toprak U, et al. Tamsulosin versus nifedipin in medical expulsive therapy for distal ureteral stones and the predictive value of Hounsfield unit in stone expulsion. Ren Fail 36: 15411544, 2014.

15. Gratzke C, Uckert S, Kedia G, Reich O, Schlenker B, Seitz $\mathrm{M}$, et al. In vitro effects of PDE5 inhibitors sildenafil, vardenafil and tadalafil on isolated human ureteral smooth muscle: a basic research approach. Urol Res 35: 49-54, 2007.

16. Itoh Y, Kojima Y, Yasui T, Tozawa K, Sasaki S, Kohri K. Examination of alpha 1 adrenoceptor subtypes in the human ureter. Int J Urol 14: 749-753, 2007.

17. Malin JM Jr, Deane RF, Boyarsky S. Characterisation of adrenergic receptors in human ureter. Br J Urol 42: 171$174,1970$.

18. Troxel SA, Jones AW, Magliola L, Benson JS. Physiologic effect of nifedipine and tamsulosin on contractility of distal ureter. J Endourol 20: 565-568, 2006.

19. Picozzi SC, Marenghi C, Casellato S, Ricci C, Gaeta M, Carmignani L. Management of ureteral calculi and medical expulsive therapy in emergency departments. J Emerg Trauma Shock 4: 70-76, 2011.

20. Yilmaz E, Batislam E, Basar MM, Tuglu D, Ferhat M, Basar H. The comparison and efficacy of 3 different alpha1-adrenergic blockers for distal ureteral stones. J Urol 173: 2010-2012, 2005.

21. Wang CJ, Huang SW, Chang CH. Efficacy of an alpha1 blocker in expulsive therapy of lower ureteral stones. J Endourol 22: 41-46, 2008.

22. Agrawal M, Gupta M, Gupta A, Agrawal A, Sarkari A, Lavania P. Prospective randomized trial comparing efficacy of alfuzosin and tamsulosin in management of lower ureteral stones. Urology 73: 706-709, 2009.

23. Huang W, Xue P, Zong H, Zhang Y. Efficacy and safety of silodosin in the medical expulsion therapy for distal ureteral calculi: a systematic review and meta-analysis. $\mathrm{Br}$ J Clin Pharmacol 81:13-22, 2016.

24. Kumar S, Jayant K, Agrawal MM, Singh SK, Agrawal S, Parmar KM. Role of tamsulosin, tadalafil, and silodosin as the medical expulsive therapy in lower ureteric stone: a randomized trial (a pilot study). Urology 85: 59-63, 2015.
25. Sahin C, Eryildirim B, Kafkasli A, Coskun A, Tarhan F, Faydaci G, Sarica K. Predictive parameters for medical expulsive therapy in ureteral stones: a critical evaluation. Urolithiasis 43: 271-275, 2015.

26. Aldaqadossi HA. Stone expulsion rate of small distal ureteric calculi could be predicted with plasma C-reactive protein. Urolithiasis 41: 235-239, 2013.

27. Singh SK, Pawar DS, Griwan MS, Indora JM, Sharma S. Role of tamsulosin in clearance of upper ureteral calculi after extracorporeal shock wave lithotripsy: a randomized controlled trial. Urol J 8: 14-20, 2011.

28. Schuler TD, Shahani R, Honey RJ, Pace KT. Medical Expulsive Therapy as an Adjunct to Improve Shockwave Lithotripsy Outcomes: A Systematic Review and MetaAnalysis. J Endourol 23: 387-393, 2009.

29. Skolarikos A, Grivas N, Kallidonis P, Mourmouris P, Rountos T, Fiamegos A, et al. The Efficacy of Medical Expulsive Therapy (MET) in Improving Stone-free Rate and Stone Expulsion Time, After Extracorporeal Shock Wave Lithotripsy (SWL) for Upper Urinary Stones: A Systematic Review and Meta-analysis. Urology 86: 10571064, 2015.

30. Yencilek F, Erturhan S, Canguven O, Koyuncu H, Erol B, Sarica K. Does tamsulosin change the management of proximally located ureteral stones? Urol Res 38: 195-199, 2010.

31. John TT, Razdan S. Adjunctive tamsulosin improves stone free rate after ureteroscopic lithotripsy of large renal and ureteric calculi: a prospective randomized study. Urology 75: 1040-1042, 2010.

32. Lamb AD, Vowler SL, Johnston R, Dunn N, Wiseman OJ. Meta-analysis showing the beneficial effect of $\alpha$-blockers on ureteric stent discomfort. BJU Int 108: 1894-1902, 2011.

33. Dellis AE, Keeley FX Jr, Manolas V, Skolarikos AA. Role of $\alpha$-blockers in the treatment of stent-related symptoms: a prospective randomized control study. Urology 83: 56-61, 2014.

34. Osorio L, Lima E, Autorino R, Marcelo F. Emergency management of ureteral stones: Recent advances. Indian J Urol 24: 461-466, 2008.

35. Pickard R, Starr K, MacLennan G, Lam T, Thomas R, Burr $\mathrm{J}$, et al. Medical expulsive therapy in adults with ureteric colic: a multicentre, randomised, placebo-controlled trial. Lancet 386: 341-349, 2015.

Yazışma Adresi:

Ali Atan,

Gazi Üniversitesi, Tıp Fakültesi, Üroloji Anabilim Dall, Ankara

Tel: +905324242082

e-mail: aliatanpitt@hotmail.com 